\title{
Phosphorus-nitrogen compounds: Part 15. Synthesis, anisochronism and the relationship between crystallographic and spectral data of monotopic spiro-crypta phosphazenes
}

\author{
NURAN ASMAFILİZ ${ }^{\mathrm{a}}$, ELIFF ECE ILTER ${ }^{\mathrm{a}}$, ZEYNEL KILIÇ $^{\mathrm{a}, *}$, TUNCER HÖKELEK ${ }^{\mathrm{b}}$ and \\ ERTAN ŞAHIN ${ }^{c}$ \\ ${ }^{a}$ Department of Chemistry, Faculty of Science, Ankara University, Tandoğan, Ankara 06100, Turkey \\ ${ }^{\mathrm{b}}$ Department of Physics, Hacettepe University, Beytepe, Ankara 06800, Turkey \\ ${ }^{\mathrm{c}}$ Department of Chemistry, Faculty of Science, Atatürk University, Erzurum 25240, Turkey \\ e-mail: zkilic@science.ankara.edu.tr
}

MS received 19 March 2008; revised 16 June 2008

\begin{abstract}
The reactions of hexachlorocyclotriphosphazatriene, $\mathrm{N}_{3} \mathrm{P}_{3} \mathrm{Cl}_{6}$, with $\mathrm{N}_{2} \mathrm{O}_{2}$-donor type coronands, $\mathrm{Ph}_{2}\left[\mathrm{OR}_{1} \mathrm{O}\right]\left[\mathrm{CH}_{2} \mathrm{NHR}_{2} \mathrm{NHCH}_{2}\right]\left[\mathrm{R}_{1}=\left(\mathrm{CH}_{2}\right)_{3}, \mathrm{R}_{2}=\left(\mathrm{CH}_{2}\right)_{3}(\mathbf{1}), \mathrm{R}_{1}=\left(\mathrm{CH}_{2}\right)_{3}, \mathrm{R}_{2}=\left(\mathrm{CH}_{2}\right)_{4}(\mathbf{2})\right.$, $\left.\mathrm{R}_{1}=\left(\mathrm{CH}_{2}\right)_{4}, \mathrm{R}_{2}=\left(\mathrm{CH}_{2}\right)_{4}(3)\right]$, give monotopic spiro-crypta phosphazene architectures, $\mathrm{N}_{3} \mathrm{P}_{3} \mathrm{Cl}_{4}\left\{\mathrm{Ph}_{2}\right.$ $\left.\left[\mathrm{OR}_{1} \mathrm{O}\right]\left[\mathrm{CH}_{2} \mathrm{NR}_{2} \mathrm{NCH}_{2}\right]\right\}\left[\mathrm{R}_{1}=\left(\mathrm{CH}_{2}\right)_{3}, \mathrm{R}_{2}=\left(\mathrm{CH}_{2}\right)_{3}(4), \mathrm{R}_{1}=\left(\mathrm{CH}_{2}\right)_{3}, \mathrm{R}_{2}=\left(\mathrm{CH}_{2}\right)_{4}(5)\right.$ and $\mathrm{R}_{1}=\left(\mathrm{CH}_{2}\right)_{4}$, $\left.\mathrm{R}_{2}=\left(\mathrm{CH}_{2}\right)_{4}(6)\right]$, respectively. The reaction of 4 with excess pyrrolidine leads to the formation of geminal $\mathrm{N}_{3} \mathrm{P}_{3} \mathrm{Cl}_{2}\left(\mathrm{C}_{5} \mathrm{H}_{5} \mathrm{~N}\right)_{2}\left\{\mathrm{Ph}_{2}\left[\mathrm{O}\left(\mathrm{CH}_{2}\right)_{3} \mathrm{O}\right]\left[\mathrm{CH}_{2} \mathrm{~N}\left(\mathrm{CH}_{2}\right)_{3} \mathrm{NCH}_{2}\right]\right\}$ (7). The ${ }^{31} \mathrm{P}-\mathrm{NMR}$ spectra of 5 and 6 indicate that these compounds have anisochronism. The structures of 5, 6 and 7 were investigated by X-ray crystallography. For 7, the sums of the bond angles around the $\mathrm{N}$ atoms were $348 \cdot 6(2)^{\circ}$ and $349 \cdot 7(2)^{\circ}$ indicating that the $\mathrm{N}$ atoms have pyramidal configurations and are stereogenic. The relationship between the chemical shift values $\delta P_{\text {(spiro) }}$ and the $\Delta(P-N)$ (electron density transfer parameters) of 4, 5, 6, 7 and the analogous compounds as well as the relationship between the $\Delta(\delta P)$ values and the above mentioned $\Delta(P-N)$ are presented respectively. In addition, the relationship between the endocyclic NPN bond angles of these compounds and the ${ }^{31} \mathrm{P}-\mathrm{NMR}$ chemical shifts of the spiro-phosphorus atoms were investigated. The spectroscopic and structural investigations of the compounds were made by elemental analyses, MS, FTIR, one-dimensional ${ }^{1} \mathrm{H}-,{ }^{13} \mathrm{C}-,{ }^{31} \mathrm{P}-\mathrm{NMR}$, DEPT and two-dimensional COSY, HETCOR, HMBC, homo- and heteronuclear correlation techniques.
\end{abstract}

Keywords. Spiro-crypta-phosphazenes; synthesis; anisochrony; spectroscopy.

\section{Introduction}

The reactions of hexachlorocyclotriphosphazatriene, $\mathrm{N}_{3} \mathrm{P}_{3} \mathrm{Cl}_{6}$, which is known as the standard compound in the field of phosphazene and polyorganophosphazene chemistry, ${ }^{1-5}$ with bulky bifunctional reagents lead to the formation of spiro-, ansa-, spiro-ansa-, binoarchitectures and cyclolinear or cyclomatrix polymers. ${ }^{6-9}$ The different substituents that are bonded to phosphorus atoms are very effective for the determination of the physical and chemical properties of new phosphazene derivatives and polyorganophosphazenes. ${ }^{10-12}$ Hence, researchers have focused on the replacement reactions of halogen atoms of halophosphazenes by different nucleophiles, e.g. primary and

*For correspondence secondary amines, ${ }^{13-15}$ diamines, ${ }^{16-18}$ diphenols, ${ }^{19-22}$ diaza-crown ethers (coronands) ${ }^{23-26}$ and aminophenols. ${ }^{27}$ In addition, chlorophosphazene derivatives have attracted increased attention and a new class of chiral phosphazene bases have been synthesized and characterized. $^{28-30}$

In recent years, our group has focused on the reactions of bulky bifunctional reagents, such as aromatic diamines, ${ }^{31}$ aminophenols, ${ }^{27}$ diphenols ${ }^{32-33}$ and diaza-crown ethers ${ }^{23-26}$ with $\mathrm{N}_{3} \mathrm{P}_{3} \mathrm{Cl}_{6}$. While the reactions of aminophenols and diaza-crown ethers with $\mathrm{N}_{3} \mathrm{P}_{3} \mathrm{Cl}_{6}$ lead respectively, to the formation of spiro- and spiro-crypta phosphazene derivatives, as major products, the condensation reaction of methylenebis(4-nitrophenol) with $\mathrm{N}_{3} \mathrm{P}_{3} \mathrm{Cl}_{6}$ yields the ansacompound, as the major product among the spiro-, spiro-spiro- and spiro-ansa-skeletons. ${ }^{32-33}$ Recently, 


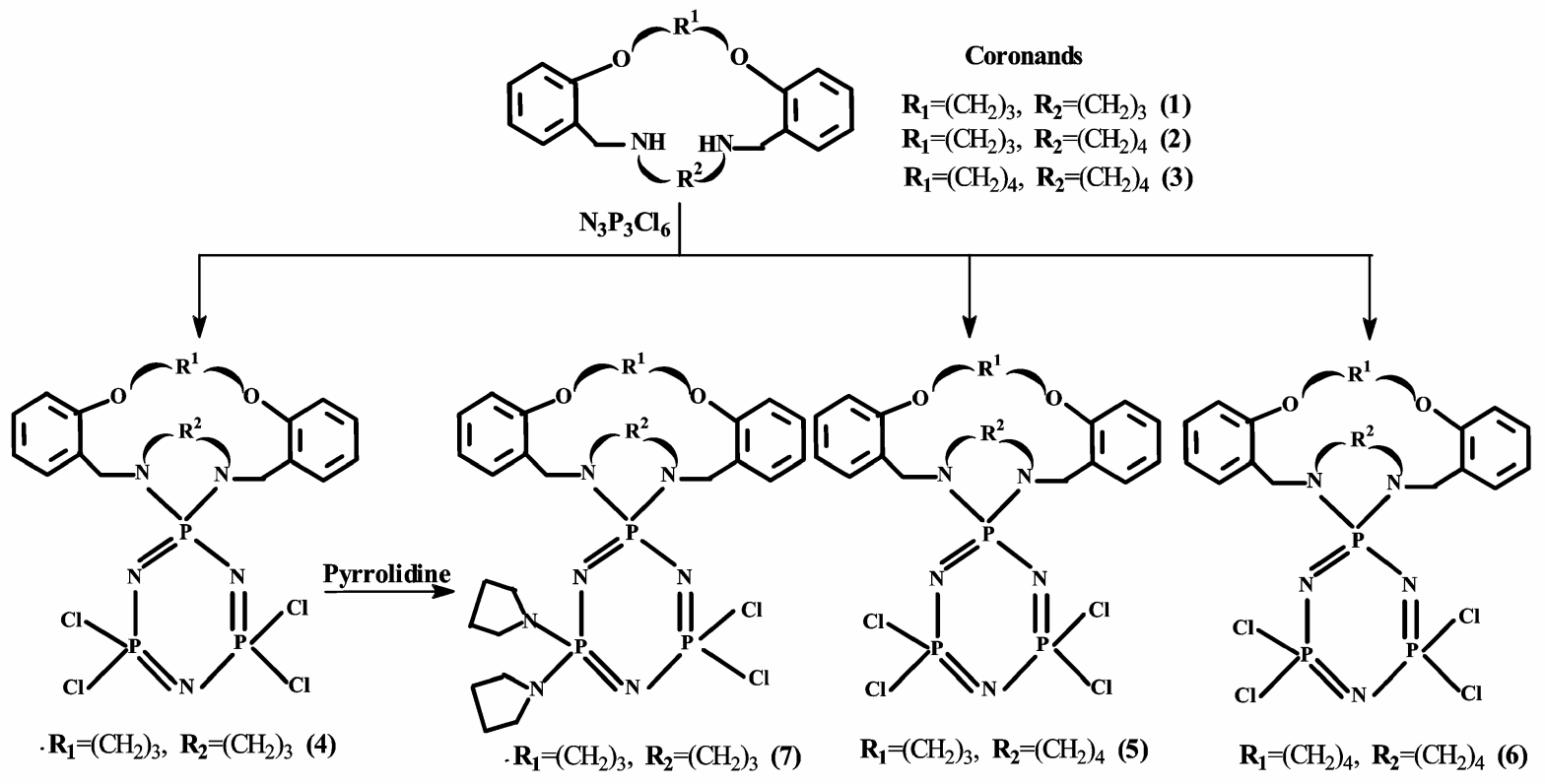

Scheme 1.

a number of interesting papers have appeared in the literature about the symmetrical ${ }^{34}$ and unsymmetrical ${ }^{35,36}$ spiro- and ansa- ${ }^{37}$ phosphazene architectures.

We report here, (i) the synthesis of spiro-crypta phosphazenes, $\mathrm{N}_{3} \mathrm{P}_{3} \mathrm{Cl}_{4}\left\{\mathrm{Ph}_{2}\left[\mathrm{OR}_{1} \mathrm{O}\right]\left[\mathrm{CH}_{2} \mathrm{NR}_{2} \mathrm{~N} \mathrm{CH}_{2}\right]\right\}$ $\left[\mathrm{R}_{1}=\left(\mathrm{CH}_{2}\right)_{3}, \quad \mathrm{R}_{2}=\left(\mathrm{CH}_{2}\right)_{4} \quad\right.$ (5) and $\mathrm{R}_{1}=\left(\mathrm{CH}_{2}\right)_{4}$, $\mathrm{R}_{2}=\left(\mathrm{CH}_{2}\right)_{4}$ (6)], from the reactions of $\mathrm{N}_{3} \mathrm{P}_{3} \mathrm{Cl}_{6}$ with the coronands (bidentate diaza-crown ethers), $\left[\mathrm{Ph}_{2}\right.$ $\left[\mathrm{OR}_{1} \mathrm{O}\right]\left[\mathrm{CH}_{2} \mathrm{NHR}_{2} \mathrm{NHCH}_{2}\right] \mathrm{R}_{1}=\left(\mathrm{CH}_{2}\right)_{3}, \mathrm{R}_{2}=\left(\mathrm{CH}_{2}\right)_{4}$ (2), $\mathrm{R}_{1}=\left(\mathrm{CH}_{2}\right)_{4}, \mathrm{R}_{2}=\left(\mathrm{CH}_{2}\right)_{4}$ (3)]; (ii) the substitutions of chloro atoms of $\mathrm{N}_{3} \mathrm{P}_{3} \mathrm{Cl}_{4}\left\{\mathrm{Ph}_{2}\left[\mathrm{O}\left(\mathrm{CH}_{2}\right)_{3} \mathrm{O}\right]\right.$ $\left.\left[\mathrm{CH}_{2} \mathrm{~N}\left(\mathrm{CH}_{2}\right)_{3} \mathrm{NCH}_{2}\right]\right\} \quad(4)^{24}$ by excess pyrrolidine that give the partly geminal substituted phosphazene $\mathrm{N}_{3} \mathrm{P}_{3} \mathrm{Cl}_{2}\left(\mathrm{C}_{5} \mathrm{H}_{5} \mathrm{~N}\right)_{2}\left\{\mathrm{Ph}_{2}\left[\mathrm{O}\left(\mathrm{CH}_{2}\right)_{3} \mathrm{O}\right]\left[\mathrm{CH}_{2} \mathrm{~N}\left(\mathrm{CH}_{2}\right)_{3} \mathrm{NCH}_{2}\right]\right\}$ (7) (scheme 1); (iii) the structures of all the compounds determined by elemental analyses, mass spectrometry (MS), Fourier transform infrared spectroscopy (FTIR), one-dimensional ${ }^{1} \mathrm{H}-,{ }^{13} \mathrm{C}$ and ${ }^{31} \mathrm{P}-$ NMR, distortionless enhancement by polarization transfer (DEPT), two-dimensional correlation spectroscopy (COSY), heteronuclear shift correlation (HETCOR), heteronuclear multiple-bond correlation (HMBC) homo- and heteronuclear correlation techniques; (iv) the X-ray structural analyses of 5, 6 and 7; (v) the relationship between the $\delta P_{(\text {(spiro) }}$-shifts and the endocyclic NPN $(\alpha)$ bond angles, and the relationship between $\Delta(P-N)$ values and $\Delta(\delta P)$ chemical shift differences as well as $\delta P_{(\text {spiro) }}$-shifts respectively.

\section{Experimental}

\subsection{General techniques}

1,4-Diaminobutane and pyrrolidine were purchased from Fluka. Hexachlorocyclotriphosphazatriene was purified by crystallization from $n$-hexane. Tetrahydrofuran (THF) was dried over molecular sieves ( $3 \AA$ ) and the other solvents were purified according to standard procedures. ${ }^{38}$ In the present study, because of the carcinogenic nature of benzene, toluene was chosen as the solvent in column chromatography investigations. All reactions were monitored using TLC in different solvents and purified by column chromatography using silica gel. Melting points were measured on a Gallenkamp apparatus by the use of capillary tubes. ${ }^{1} \mathrm{H}-,{ }^{13} \mathrm{C},{ }^{31} \mathrm{P}-\mathrm{NMR}$, HETCOR, COSY, DEPT and HMBC spectra were obtained on a Bruker DPX FT-NMR (500 MHz) spectrometer $\left(\mathrm{SiMe}_{4}\right.$ as internal standard and $85 \% \mathrm{H}_{3} \mathrm{PO}_{4}$ as an external standard). The spectrometer was equipped with a $5 \mathrm{~mm}$ PABBO BB inverse gradient probe. Standard Bruker pulse programs ${ }^{39}$ were used in the experiments. FTIR spectra were obtained on a Mattson 1000 FTIR spectrometer in $\mathrm{KBr}$ discs. Elemental analyses were carried out by the Microanalytical Service of TUBITAK-ATAL, Ankara. Electrospray ionization mass spectra (ESI-MS) were recorded on an AGILENT 1100 MSD spectrometer. 


\subsection{Synthesis of compounds}

2,6-Dioxa-14,18-diazatricyclo-[18.4.0.0 $\left.0^{7,12}\right]$-tetracosa7, 9, 11, 20, 22, 24(1)-hexaene 1, 2,6-dioxa-14,19diazatricyclo-[19.4.0.0 $\left.0^{7,12}\right]$-pentacosa-7, 9, 11, 21, 23, 25(1)-hexaene 2 and 2,7-dioxa-15,19-diazatricyclo-[19.4.0.0.1.13]-pentacosa-8, 10, 12, 21, 23, 25(1)hexaene $3^{40,41}$ were prepared according to the cited procedures. Also compound 4 was obtained from the reaction of 1 with $\mathrm{N}_{3} \mathrm{P}_{3} \mathrm{Cl}_{6}$ according to the reported method. ${ }^{24}$

2.2a Synthesis of 7,12-[propane-1,3-diyldioxydi-ophenylene-dimethylene]-2,2,4,4-tetrachloro- $2 \lambda^{5}, 4 \lambda^{5}$, $6 \lambda^{5}$-tri phosphaza(6-P $\left.P^{v}\right)-1,3,5,7,12-$ pentazaspiro [6.5] trideca-1,3,5-triene (5): A solution of $\mathrm{N}_{3} \mathrm{P}_{3} \mathrm{Cl}_{6}$ $(3.34 \mathrm{~g}, 9.60 \mathrm{mmol})$ in dry THF $(50 \mathrm{~mL})$ and $\mathrm{Et}_{3} \mathrm{~N}$ $(2.67 \mathrm{ml}, 19.20 \mathrm{mmol})$ were slowly added to a solution of coronand $2(3.00 \mathrm{~g}, 9.60 \mathrm{mmol})$ in THF $(100 \mathrm{~mL})$. The mixture was stirred for 2 days and the solvent was evaporated. The product was purified by column chromatography using toluene as the eluent. A white product was crystallized from ethyl acetate (yield: $2.40 \mathrm{~g}, 44 \%$, m.p.: $215^{\circ} \mathrm{C}$ ). Anal. Calcd. for $\mathrm{C}_{21} \mathrm{H}_{26} \mathrm{~N}_{5} \mathrm{O}_{2} \mathrm{P}_{3} \mathrm{Cl}_{4}$ : C 40.99, $\mathrm{H} 4 \cdot 26, \mathrm{~N}$ $10.38 \%$. Found: C $41.02, \mathrm{H} 4.28, \mathrm{~N} 11.51 \%$. IR (KBr, $\mathrm{cm}^{-1}$, selected peaks): $3067 v$ (aromatic $\mathrm{CH}$ asymm.), $3030 v$ (aromatic $\mathrm{CH}$ symm.), 1242, $1182 v(\mathrm{P}=\mathrm{N}), 1151$ $v(\mathrm{C}-\mathrm{O}), 571 s, 509 v\left(\mathrm{PCl}_{2}\right)$. MS (ESI) (fragments based on $\left.{ }^{35} \mathrm{Cl}, \mathrm{Ir} \%\right): m / z=613\left(\mathrm{M}^{+}, 80 \%\right)$.

2.2b Synthesis of 7,12-[butane-1,4-diyldioxydi-ophenylene-dimethylene ]-2,2,4,4-tetrachloro-2 $\lambda^{5}, 4 \lambda^{5}$, $6 \lambda^{5}$-tri phosphaza $\left(6-P^{v}\right)-1,3,5,7,12$-pentazaspiro [6.5] trideca-1,3,5-triene (6): The work-up procedure is the same as that of compound 5 , using $\mathrm{N}_{3} \mathrm{P}_{3} \mathrm{Cl}_{6}(2 \cdot 10 \mathrm{~g}$, $6.00 \mathrm{mmol}), \mathrm{Et}_{3} \mathrm{~N} \quad(1.69 \mathrm{ml}, 12.00 \mathrm{mmol})$ and coronand $3(2.14 \mathrm{~g}, 6.00 \mathrm{mmol})$. The product was purified by column chromatography using toluene as the eluent and crystallized from ethyl acetate (yield: $2.00 \mathrm{~g}, 53 \%$, m.p.: $157-159^{\circ} \mathrm{C}$ ). Anal. Calcd. for $\mathrm{C}_{22} \mathrm{H}_{28} \mathrm{~N}_{5} \mathrm{O}_{2} \mathrm{P}_{3} \mathrm{Cl}_{4}: \mathrm{C} 41.99, \mathrm{H} \quad 4.48, \mathrm{~N} 11.13 \%$. Found: C $41.79, \mathrm{H} 5 \cdot 51, \mathrm{~N} 10 \cdot 87 \%$. IR $\left(\mathrm{KBr}, \mathrm{cm}^{-1}\right.$, selected peaks): $3069 v$ (aromatic $\mathrm{CH}$ asymm.), 3022 $v($ aromatic $\mathrm{CH}$ symm. $), 1236,1176 v(\mathrm{P}=\mathrm{N}), 1157$ $v(\mathrm{C}-\mathrm{O}), 567,511 v\left(\mathrm{PCl}_{2}\right)$. MS (ESI) (fragments based on $35 \mathrm{Cl}, \mathrm{Ir} \%): m / z=627\left(\mathrm{M}^{+}, 79 \%\right)$.

2.2c Synthesis of 7,11-[propane-1,3-diyldioxydi-ophenylene-dimethylene]-2,2-dichloro-4,4-bis pyrrolidino-2 $\lambda^{5}, 4 \lambda^{5}, 6 \lambda^{5}$-triphosphaza(6-P $)-1,3,5,7,11$ pentazaspiro [5.5] dodeca-1,3,5-triene (7): A solu- tion of compound $4(0.45 \mathrm{~g}, 0.70 \mathrm{mmol})$ in dry THF $(150 \mathrm{ml})$ was added slowly to a solution of pyrrolidine $(0.70 \mathrm{ml}, 8.40 \mathrm{mmol})$ with stirring and refluxing for $30 \mathrm{~h}$. After the evaporation of THF, the mixture was dissolved in benzene $(150 \mathrm{ml})$ and excess of triethylamine $(0.40 \mathrm{ml}, 3.00 \mathrm{mmol})$ was added to the solution. The mixture was refluxed for $4 \mathrm{~h}$ and the product was purified by coloumn chromatography using toluene/THF $(5: 1)$ mixture as the eluent and crystallized from $n$-heptane (yield: $0.20 \mathrm{~g}$, $40 \%$, m.p.: $163-165^{\circ} \mathrm{C}$ ). Anal. Calcd. for $\mathrm{C}_{28} \mathrm{H}_{40}$ $\mathrm{N}_{7} \mathrm{O}_{2} \mathrm{P}_{3} \mathrm{Cl}_{2}$ : C 50.16, H 6.01, N 14.62\%. Found: C $50.96, \mathrm{H} 5.83, \mathrm{~N} 14.53 \%$. IR $\left(\mathrm{KBr}, \mathrm{cm}^{-1}\right.$, selected peaks): $3065 v$ (aromatic $\mathrm{CH}$ asymm.), $3020 v$ (aromatic $\mathrm{CH}$ symm. $), 1219,1178 v(\mathrm{P}=\mathrm{N}), 1124 v(\mathrm{C}-\mathrm{O}), 581$, $513 v\left(\mathrm{PCl}_{2}\right)$. MS (ESI) (fragments based on ${ }^{35} \mathrm{Cl}$, $\operatorname{Ir} \%): m / z=670\left[(\mathrm{MH})^{+}, 100 \%\right]$.

\section{$2.3 X$ X-Ray crystallography}

Colourless crystals of $\mathbf{5}$ and $\mathbf{6}$ were crystallized from ethyl acetate, while 7 was grown from $n$-heptane at room temperature.

The molecular structures and the packing diagrams of compounds (5, 6 and 7) along with the atom-numbering schemes are depicted in figures 1 , 2 and 3, respectively. The crystallographic data are listed in table 1 and the selected bond lengths and angles are given in table 2 . The crystallographic data were collected on a Rigaku R-AXIS RAPID-S diffractometer using $\operatorname{MoK}_{\alpha}$ radiation $(\lambda=0.71073 \AA)$ at $\mathrm{T}=293 \mathrm{~K}$. Absorption corrections by multi-scan ${ }^{42}$ were applied. Structures were solved by direct methods $^{43}$ and refined by full-matrix least squares against $F^{2}$ using all data. ${ }^{43}$ All non-H atoms were refined anisotropically. The $\mathrm{H}$ atom positions were calculated geometrically at distances of $0.93(\mathrm{CH})$ and $0.97 \AA\left(\mathrm{CH}_{2}\right)$ from the parent $\mathrm{C}$ atoms; a riding model was used during the refinement process and the $\mathrm{U}_{\text {iso }}(\mathrm{H})$ values were constrained to be $1 \cdot 2 \mathrm{U}_{\mathrm{eq}}$ (carrier atom).

\section{Results and discussion}

\subsection{Synthesis}

Monotopic spiro-crypta phosphazenes, $\mathbf{5}$ and $\mathbf{6}$, were synthesized from the reaction of $\mathrm{N}_{3} \mathrm{P}_{3} \mathrm{Cl}_{6}$ with the coronands, $\mathbf{2}$ and $\mathbf{3}$ (scheme 1), in dry THF with excess $\mathrm{Et}_{3} \mathrm{~N}$ as the $\mathrm{HCl}$ acceptor. These reactions are likely to be regioselective, similar to the behaviour 


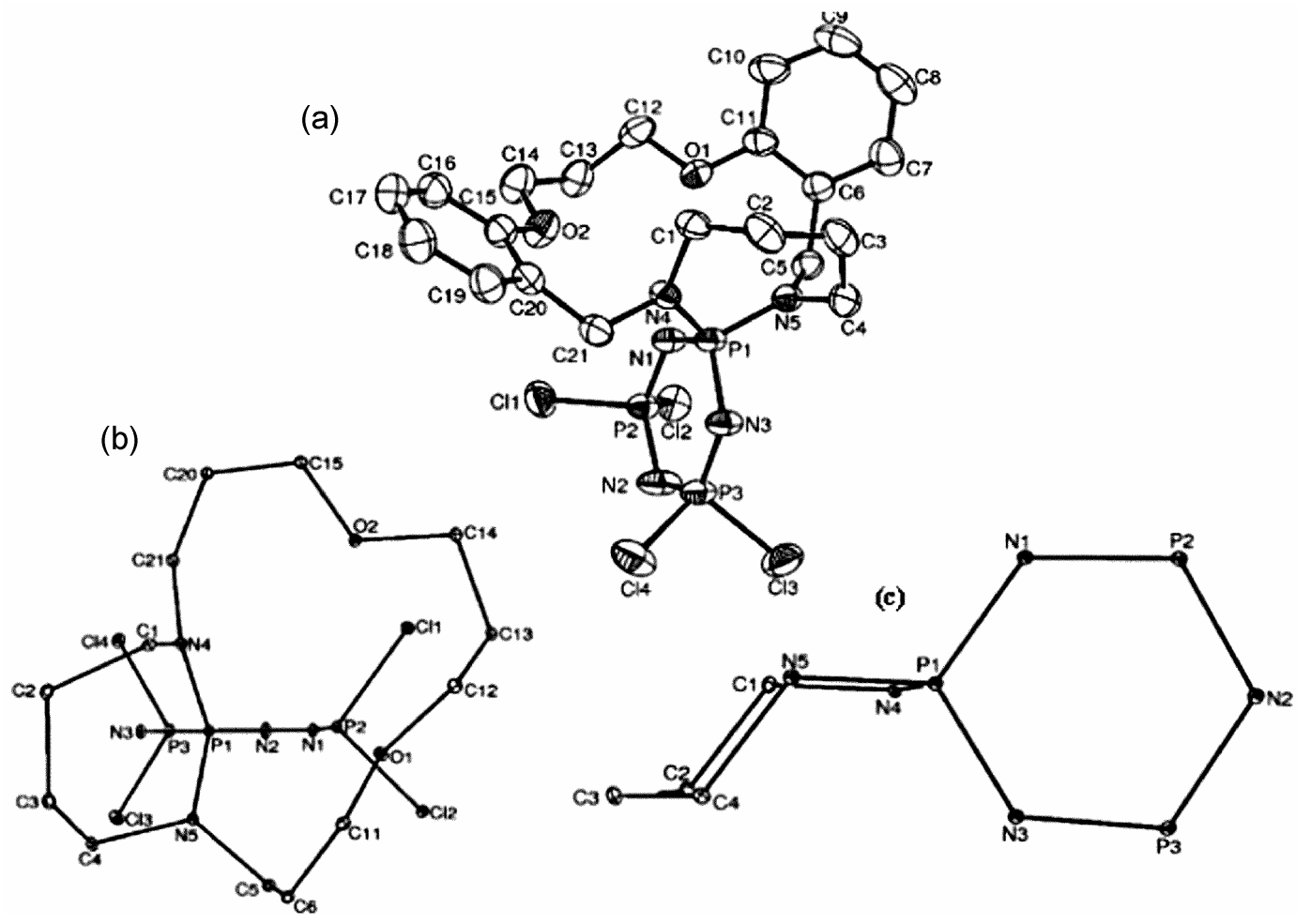

Figure 1. (a) An ORTEP- $3^{44}$ drawing of 5 with the atom-numbering scheme. Displacement ellipsoids are drawn at the $30 \%$ probability level. (b) The conformations of the phosphazene and the macro rings. (c) The conformation of the seven-membered spiro-ring.

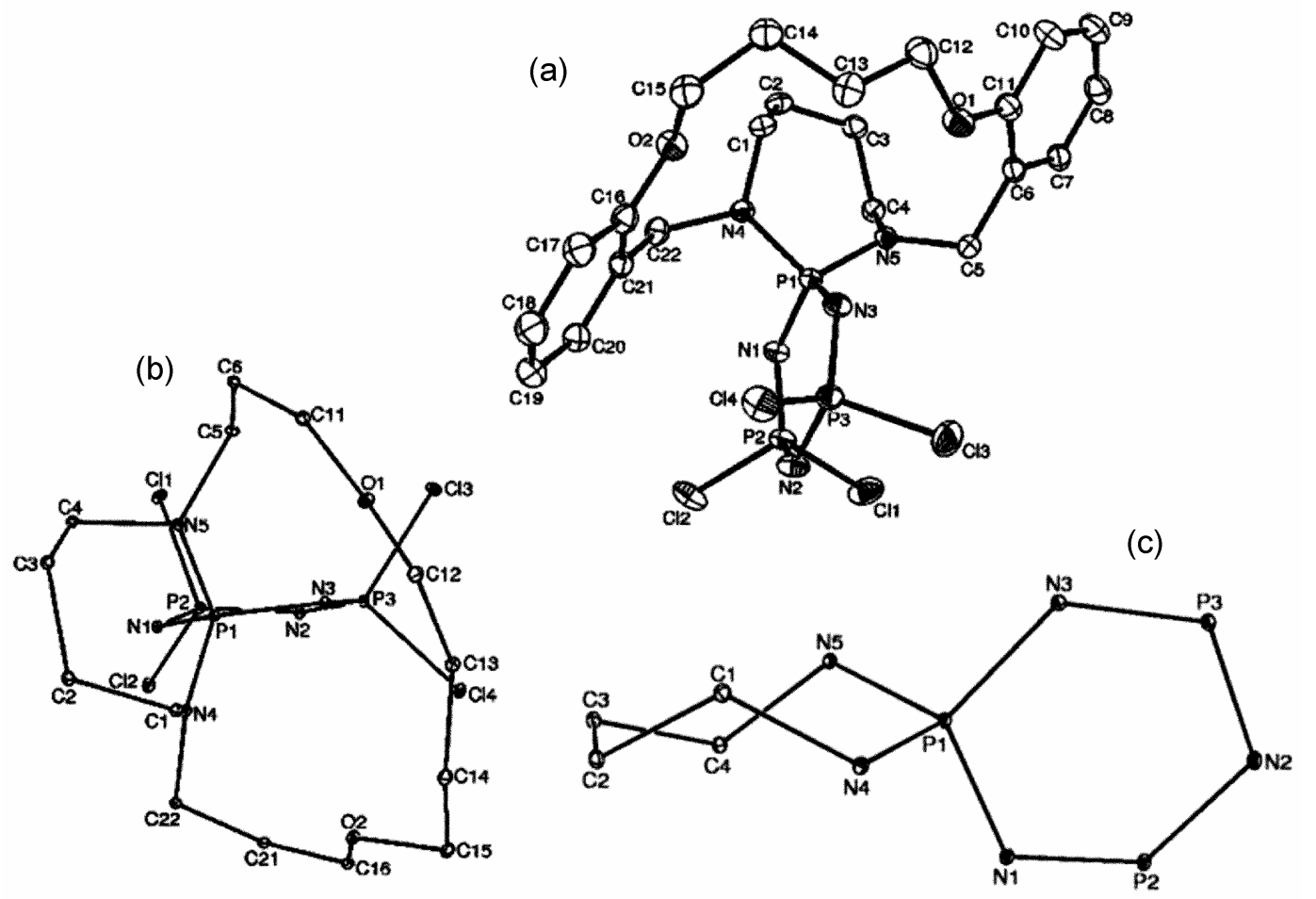

Figure 2. (a) An ORTEP- $3^{44}$ drawing of 6 with the atom-numbering scheme. Displacement ellipsoids are drawn at the $30 \%$ probability level. (b) The conformations of the phosphazene and the macro rings. (c) The conformation of the seven-membered spiro-ring. 

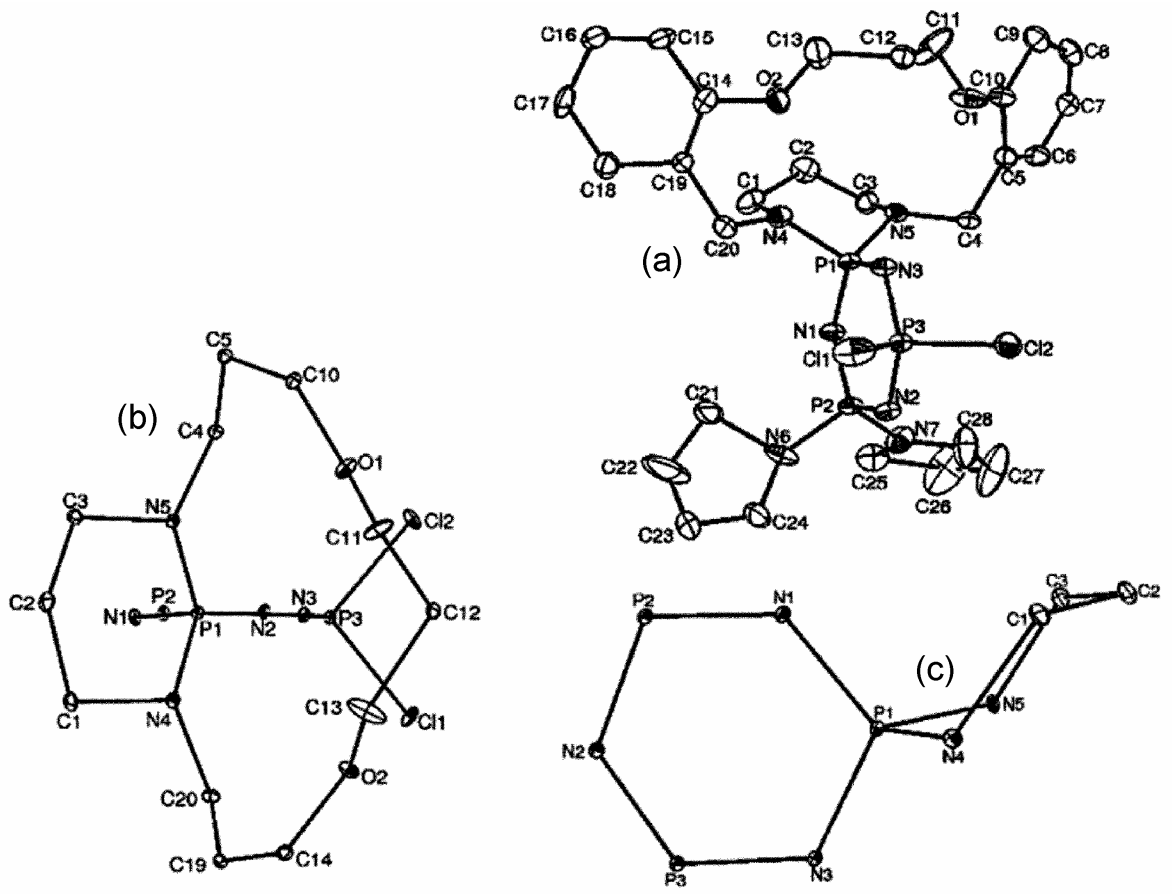

Figure 3. (a) An ORTEP- $3^{44}$ drawing of 7 with the atom-numbering scheme. Displacement ellipsoids are drawn at the $30 \%$ probability level. (b) The conformations of the phosphazene and the macro rings. (c) The conformation of the six-membered spiro-ring.

Table 1. Crystallographic data of 5,6 and 7 .

\begin{tabular}{|c|c|c|c|}
\hline & (5) $\mathrm{C}_{21} \mathrm{H}_{26} \mathrm{Cl}_{4} \mathrm{~N}_{5} \mathrm{O}_{2} \mathrm{P}_{3}$ & (6) $\mathrm{C}_{22} \mathrm{H}_{28} \mathrm{Cl}_{14} \mathrm{~N}_{5} \mathrm{O}_{2} \mathrm{~F}$ & ) $\mathrm{C}_{28} \mathrm{H}_{38} \mathrm{Cl}_{12} \mathrm{~N}_{7} \mathrm{O}_{2} \mathrm{P}_{3}$ \\
\hline $\begin{array}{l}\text { Empirical formula } \\
F_{w}\end{array}$ & $\begin{array}{l}\mathrm{C}_{21} \mathrm{H}_{26} \mathrm{Cl}_{14} \mathrm{~N}_{5} \mathrm{O}_{2} \mathrm{P}_{3} \\
615.18\end{array}$ & $\begin{array}{l}\mathrm{C}_{222} \mathrm{H}_{28} \mathrm{Cl}_{14} \mathrm{~N}_{5} \mathrm{O}_{2} \mathrm{P}_{3} \\
629.20\end{array}$ & $\begin{array}{l}\mathrm{C}_{28} \mathrm{H}_{38} \mathrm{Cl}_{12} \mathrm{~N}_{7} \mathrm{O}_{2} \mathrm{P}_{3} \\
668.46\end{array}$ \\
\hline Crystal system & orthorhombic & monoclinic & orthorhombic \\
\hline Space group & $P 2_{1} 2_{1} 2_{1}$ & $P 2_{1} / c$ & $P \mathrm{c} 2{ }_{1} n$ \\
\hline$a(\AA)$ & $7.9595(1)$ & $10 \cdot 019(5)$ & $9 \cdot 503(5)$ \\
\hline$b(\AA)$ & $17 \cdot 8168(2)$ & $15 \cdot 369(5)$ & $17 \cdot 955(5)$ \\
\hline$c(\AA)$ & $19 \cdot 3514(3)$ & $18 \cdot 682(5)$ & $19 \cdot 721(5)$ \\
\hline$\alpha\left({ }^{\circ}\right)$ & $90 \cdot 00$ & $90 \cdot 00$ & 90.00 \\
\hline$\beta\left({ }^{\circ}\right)$ & $90 \cdot 00$ & $98.679(5)$ & 90.00 \\
\hline$\gamma\left({ }^{\circ}\right)$ & $90 \cdot 00$ & $90 \cdot 00$ & 90.00 \\
\hline$V\left(\AA^{3}\right)$ & $2744 \cdot 28(6)$ & $2843 \cdot 8(19)$ & $3365(2)$ \\
\hline$Z$ & 4 & 4 & 4 \\
\hline$\mu(\mathrm{MoK})\left(\mathrm{cm}^{-1}\right)$ & 0.636 & 0.615 & 0.703 \\
\hline$\rho$ (calcd) $\left(\mathrm{g} \mathrm{cm}^{-1}\right)$ & 1.489 & 1.470 & $1 \cdot 320$ \\
\hline Number of reflections tot & 75338 & 81976 & 92485 \\
\hline Number of reflections unique & 8387 & 8689 & 9943 \\
\hline$R_{\text {int }}$ & 0.0517 & $0 \cdot 0644$ & $0 \cdot 0687$ \\
\hline $2 \theta_{\max }\left({ }^{\circ}\right)$ & $61 \cdot 20$ & $61 \cdot 36$ & $61 \cdot 12$ \\
\hline$T_{\min } / T_{\max }$ & $0 \cdot 8081 / 0.9106$ & $0.863 / 0.912$ & $0.8081 / 0.9106$ \\
\hline Number of parameters & 316 & 326 & 379 \\
\hline$R\left[F^{2}>2 \sigma\left(F^{2}\right)\right]$ & 0.0437 & 0.0518 & 0.0854 \\
\hline$w R$ & 0.0943 & $0 \cdot 1372$ & $0 \cdot 2454$ \\
\hline
\end{tabular}

of homologous compounds. ${ }^{23}$ The geminal substituted spiro-crypta phosphazene 7 has been prepared by means of the reaction of 4 with excess pyrrolidine. In the literature ${ }^{45-47}$ it is indicated that the secondary amines, e.g. pyrrolidine and diethyl amine show non-geminal bonding. However, contrarily to these observations in 7 , pyrrolidines show geminal bonding preference instead of non-geminal bonding. 
Table 2. The selected bond lengths $(\AA)$ and angles $\left(^{\circ}\right)$ with the selected torsion angles $\left({ }^{\circ}\right)$ for $\mathbf{5}, 6$ and 7.

\begin{tabular}{|c|c|c|c|c|c|}
\hline \multicolumn{2}{|l|}{5} & \multicolumn{2}{|c|}{6} & \multicolumn{2}{|l|}{7} \\
\hline P1-N1 & $1 \cdot 610(2)$ & P3-N2 & $1 \cdot 582(2)$ & P1-N1 & $1.587(3)$ \\
\hline P1-N5 & $1 \cdot 621(2)$ & P1-N4 & $1 \cdot 624(2)$ & P1-N3 & $1 \cdot 603(3)$ \\
\hline P1-N3 & $1.622(2)$ & P3-N3 & $1 \cdot 549(2)$ & P1-N4 & $1.609(6)$ \\
\hline P1-N4 & $1.632(2)$ & P1-N5 & $1 \cdot 629(2)$ & P1-N5 & $1.675(5)$ \\
\hline $\mathrm{P} 2-\mathrm{N} 1$ & $1 \cdot 5476(19)$ & P1-N3 & $1 \cdot 617(2)$ & P3-N2 & $1.545(3)$ \\
\hline $\mathrm{P} 2-\mathrm{N} 2$ & $1.577(2)$ & P1-N1 & $1 \cdot 626(2)$ & P3-N3 & $1 \cdot 562(3)$ \\
\hline $\mathrm{P} 2-\mathrm{Cl} 2$ & $1.9948(10)$ & $\mathrm{P} 2-\mathrm{Cl} 2$ & $2 \cdot 0051(11)$ & P3-Cl1 & $2 \cdot 008(3)$ \\
\hline $\mathrm{P} 2-\mathrm{Cl} 1$ & $2 \cdot 0159(10)$ & $\mathrm{P} 2-\mathrm{Cl} 1$ & $2 \cdot 0139(11)$ & $\mathrm{P} 3-\mathrm{Cl} 2$ & $2 \cdot 023(3)$ \\
\hline P3-N3 & $1 \cdot 545(2)$ & $\mathrm{P} 2-\mathrm{N} 2$ & $1 \cdot 580(2)$ & P2-N1 & $1 \cdot 568(3)$ \\
\hline $\mathrm{P} 3-\mathrm{N} 2$ & $1 \cdot 586(2)$ & $\mathrm{P} 2-\mathrm{N} 1$ & $1 \cdot 546(2)$ & $\mathrm{P} 2-\mathrm{N} 7$ & $1.607(8)$ \\
\hline P3-Cl4 & $2 \cdot 0010(11)$ & P3-Cl4 & $1.9977(11)$ & $\mathrm{P} 2-\mathrm{N} 2$ & $1.620(3)$ \\
\hline $\mathrm{P} 3-\mathrm{Cl} 3$ & $2 \cdot 0020(11)$ & P3-Cl3 & $2 \cdot 0180(11)$ & P2-N6 & $1 \cdot 645(8)$ \\
\hline N1-P1-N3 & $111 \cdot 88(10)$ & N3-P1-N1 & $112 \cdot 32(11)$ & N1-P1-N3 & $114 \cdot 35(16)$ \\
\hline N1-P2-N2 & $120 \cdot 41(11)$ & N1-P2-N2 & $119.93(11)$ & N2-P3-N3 & $122 \cdot 77(17)$ \\
\hline N3-P3-N2 & $119 \cdot 80(11)$ & N3-P3-N2 & $120 \cdot 10(11)$ & N1-P2-N2 & $114 \cdot 01(16)$ \\
\hline P3-N3-P1 & $124 \cdot 89(12)$ & P2-N1-P1 & $122 \cdot 57(13)$ & $\mathrm{P} 3-\mathrm{N} 3-\mathrm{P} 1$ & $120 \cdot 18(18)$ \\
\hline $\mathrm{P} 2-\mathrm{N} 1-\mathrm{P} 1$ & $124 \cdot 58(12)$ & P3-N3-P1 & $124 \cdot 31(13)$ & P2-N1-P1 & $127 \cdot 7(2)$ \\
\hline P2-N2-P3 & $118 \cdot 25(13)$ & P2-N2-P3 & $117 \cdot 10(13)$ & P3-N2-P2 & $120 \cdot 51(19)$ \\
\hline $\mathrm{C} 5-\mathrm{N} 5-\mathrm{C} 4$ & $117 \cdot 4(2)$ & C5-N5-C4 & $116 \cdot 50(19)$ & C3-N5-C4 & $116 \cdot 4(6)$ \\
\hline C5-N5-P1 & $124 \cdot 61(17)$ & C5-N5-P1 & $124 \cdot 08(16)$ & C3-N5-P1 & $114 \cdot 1(5)$ \\
\hline C4-N5-P1 & $117 \cdot 80(17)$ & C4-N5-P1 & $117 \cdot 31(15)$ & C4-N5-P1 & $118 \cdot 1(4)$ \\
\hline Cl-N4-C21 & $118 \cdot 2(2)$ & $\mathrm{C} 22-\mathrm{N} 4-\mathrm{Cl}$ & $117 \cdot 1(2)$ & $\mathrm{C} 20-\mathrm{N} 4-\mathrm{Cl}$ & $113 \cdot 6(7)$ \\
\hline Cl-N4-P1 & $123 \cdot 97(16)$ & C22-N4-P1 & $121 \cdot 00(17)$ & C20-N4-P1 & $121 \cdot 2(5)$ \\
\hline C21-N4-P1 & $117 \cdot 27(16)$ & C1-N4-P1 & $121 \cdot 66(17)$ & Cl-N4-P1 & $114 \cdot 9(5)$ \\
\hline N2-P3-N3-P1 & $1 \cdot 4(3)$ & N2-P2-N1-P1 & $22 \cdot 7(2)$ & N2-P2-N1-P1 & $4 \cdot 6(8)$ \\
\hline N1-P1-N3-P3 & $-0 \cdot 6(2)$ & N3-P1-N1-P2 & $-11 \cdot 4(2)$ & N3-P1-N1-P2 & $-6 \cdot 7(9)$ \\
\hline N2-P2-N1-P1 & $-4 \cdot 5(3)$ & N2-P3-N3-P1 & $-0 \cdot 3(2)$ & N3-P3-N2-P2 & $-6 \cdot 4(8)$ \\
\hline N3-P1-N1-P2 & $2 \cdot 2(2)$ & N1-P1-N3-P3 & $0 \cdot 3(2)$ & $\mathrm{N} 1-\mathrm{P} 2-\mathrm{N} 2-\mathrm{P} 3$ & $2 \cdot 2(7)$ \\
\hline N1-P2-N2-P3 & $4 \cdot 9(3)$ & N1-P2-N2-P3 & $-21 \cdot 5(2)$ & $\mathrm{N} 2-\mathrm{P} 3-\mathrm{N} 3-\mathrm{P} 1$ & $4 \cdot 1(9)$ \\
\hline N3-P3-N2-P2 & $-3 \cdot 4(3)$ & N3-P3-N2-P2 & $10 \cdot 6(2)$ & N1-P1-N3-P3 & $2 \cdot 1(8)$ \\
\hline
\end{tabular}

The possible reasons may be; (i) the macrocycle may hinder the attack of the pyrrolidine molecule to one of the $>\mathrm{PCl}_{2}$ groups, and (ii) there may be a mechanistic switch during the formation of 7 . The geminal structure of 7 has been determined by X-ray structural analyses (figure 3a).

The microanalyses, FTIR, ESI-MS spectra, NMR and crystallographic data are consistent with the proposed structures of $\mathbf{5 , 6}$, and $\mathbf{7}$. While the mass spectra of 5 and $\mathbf{6}$ show the molecular ion $\left(\mathrm{M}^{+}\right)$peaks at $\mathrm{m} / \mathrm{z} 613$ and 627, the MS spectra of 7 shows a $(\mathrm{MH})^{+}$peak at $m / z 670$.

\subsection{Spectroscopic analyses}

The FTIR spectra of 5, 6 and 7 exhibit two weak intensity bands at $3069-3065 \mathrm{~cm}^{-1}$ and $3030-3020 \mathrm{~cm}^{-1}$ attributed to the asymmetric stretching vibrations of aromatic $\mathrm{CH}$-bonds. Two kinds of $v \mathrm{P}=\mathrm{N}$ absorption peaks are observed for mono spiro-crypta phosphazenes at $1242-1219 \mathrm{~cm}^{-1}$ and $1182-1176 \mathrm{~cm}^{-1}$. The characteristic $v \mathrm{~N}-\mathrm{H}$ bands of 2 (at $3412 \mathrm{~cm}^{-1}$ ) and $3\left(\right.$ at $\left.3468 \mathrm{~cm}^{-1}\right)$ disappear in the IR spectra of 5 and 6. Two kinds of absorption frequencies for $>\mathrm{PCl}_{2}$ bonds of the partially substituted phosphazenes $\mathbf{5 , 6}$ and 7 are observed in the range of $581-567 \mathrm{~cm}^{-1}$ and $513-509 \mathrm{~cm}^{-1}$.

The proton decoupled ${ }^{31} \mathrm{P}-\mathrm{NMR}$ spectral data of $4,^{24} 5,6$ and 7 , and analogous spiro-crypta phosphazenes (I-VII) ${ }^{23,24,26,48}$ are listed in table 3. The ${ }^{31} \mathrm{P}$-NMR spectra of 5, 6 and 7 are interpreted as $\mathrm{ABX}, \mathrm{ABX}$ and AMX, respectively.

The torsion angles (table 2) indicate that the two $\mathrm{N}$ atoms bonded to the spiro-P atom are approximately perpendicular to the $\mathrm{N}_{3} \mathrm{P}_{3}$ ring (figures $1 \mathrm{~b}$ and $2 \mathrm{~b}$ ) and in compounds 5 and $\mathbf{6}$, its substituent $\mathrm{R}^{1}$ and $\mathrm{R}^{2}$ (scheme 1) project sideways, and thus the two $>\mathrm{PCl}_{2}$ groups are in different environments, leading an 
asymmetry. Since $\mathrm{R}^{1}$ and $\mathrm{R}^{2}$ differ, one might expect the anisochronism of the two $>\mathrm{PCl}_{2}$ groups, as it was observed for $4^{24}$ and other analogous compounds (I, II, III and V) ${ }^{23,24,26}$ The ${ }^{31}$ P-NMR spectra of 5 and $\mathbf{6}$ consist of doublets of doublet for each of the phosphorus atoms, due to the anisochrony (figure 4). In addition, as expected compound 7 has also three doublets of doublet for $\delta P(\text { pyrr })_{2}(14.30 \mathrm{ppm}), \delta P($ spiro $)$ $(18.33 \mathrm{ppm})$ and $\delta P \mathrm{Cl}_{2}(27.20 \mathrm{ppm})$. In the literature, ${ }^{25}$ for six-membered spiro-crypta phosphazene derivatives, it was concluded that if the ${ }^{2} \mathbf{J}_{\mathrm{PP}}$ values are nearly the same, then the two nitrogen atoms in the spiro-ring have pyramidal configurations (stereogenic), if two of the ${ }^{2} \mathbf{J}_{\mathrm{PP}}$ values are approximately
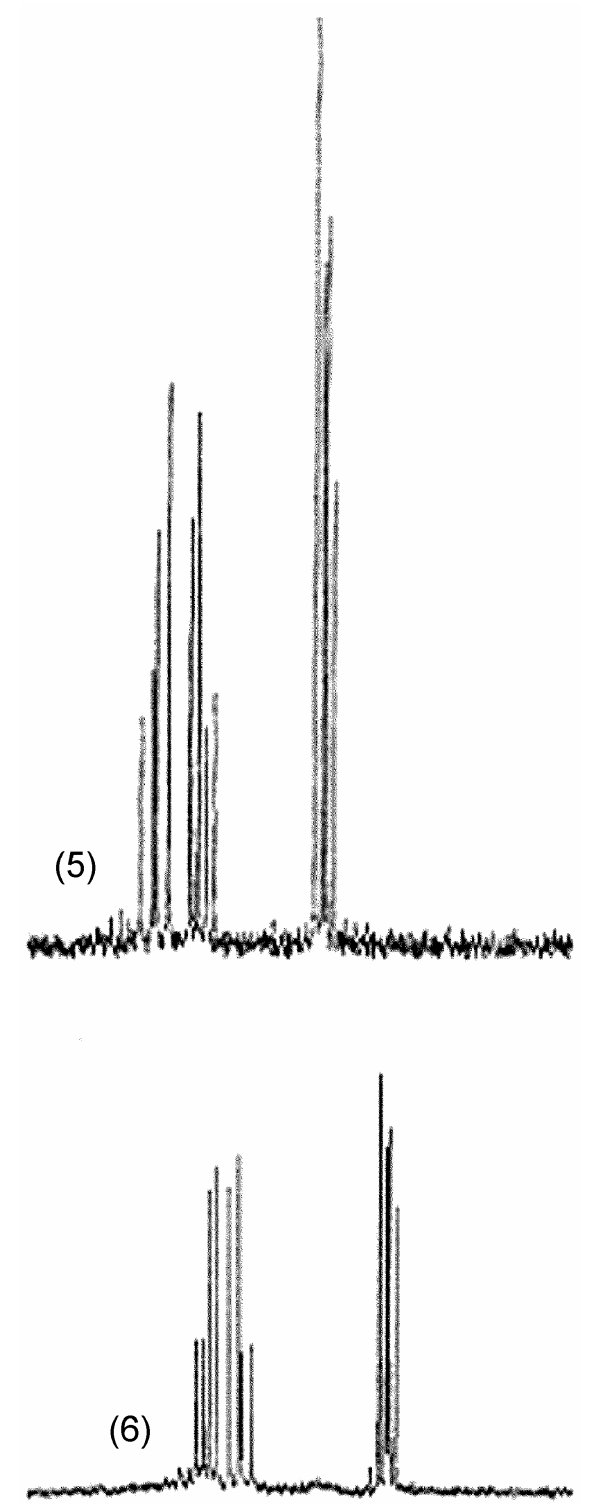

Figure 4. Anisochronism of 5 and 6. the same, then one nitrogen atom has pyramidal configuration, and if all the three of the ${ }^{2} \mathbf{J}_{\mathrm{PP}}$ values are different, then no nitrogen atom has pyramidal configuration. Compounds 5 and $\mathbf{6}$ have seven-membered spiro-rings and all three of the ${ }^{2} J_{\mathrm{PP}}$ values are different (table 3), hence, no nitrogen atom in the spiroring has pyramidal configuration. These findings are in accordance with the data obtained from the X-ray crystallography of $\mathbf{5}$ and $\mathbf{6}$ (the sums of the bond angles around N4 and N5 are $359.4(2)^{\circ}$ and $359.8(2)^{\circ}$; $359.8(2)^{\circ}$ and $357.9(2)^{\circ}$, respectively).

The $\alpha$ angles and the $\delta P_{(\text {(spiro) }}$-shifts of the spirocrypta phosphazenes $(\mathbf{5}, \mathbf{6}$ and 7) presented in this study and the analogous compounds (4 and I-VII) taken from the literature are listed in table 3. The $\delta P_{\text {(spiro) }}$-shifts of the crypta-phosphazenes (4-7 and I-VII) and the standard compound $\mathrm{N}_{3} \mathrm{P}_{3} \mathrm{Cl}_{6}$ versus $\alpha$-angles are shown in figure $5 \mathrm{a}$. In this graph, one can easily observe two separate regions, A and B. In region $\mathrm{A}$, monotopic tetrachloro-, and in region $\mathrm{B}$, ditopic and pyrrolidinyl-substituted dichloro spirocrypta phosphazenes are accumulated. These appear as a 'cluster' of points. However, a linearity between the $\delta P$-shifts and $\alpha$ angles has been observed for spirocyclic phosphaza lariat ethers ${ }^{25}$ and spiro-cyclic (NPO) phosphazene derivatives. ${ }^{49}$ The order of $\alpha$ values are; $\mathrm{N}_{3} \mathrm{P}_{3} \mathrm{Cl}_{6}>$ the compounds in region $\mathrm{B}$ cycle $>$ the compounds in region A cycle in figure 5a.

The electron releasing or withdrawing power of the substitutents bonded to the phosphorus atoms of the $\mathrm{N}_{3} \mathrm{P}_{3}$ ring, $\Delta(P-N)$ (electron density transfer parameters: the difference between the bond lengths of two adjacent $P-N$ bonds ${ }^{50,51}$ are also listed in table 3 . The relationships between $\Delta(P-N)$ with the $\delta P_{\text {(spiro)- }}$ shifts, and $\Delta(\delta P)$ values (4-7 and I-VII) are illustrated in figures $5 \mathrm{~b}$ and $5 \mathrm{c}$, respectively. In figure $5 \mathrm{~b}$, the electron releasing power of pyrrolidinyl-substituted dichloro and ditopic spiro-crypta phosphazenes are greater than those of the monotopic spiro-crypta phosphazene derivatives. In addition, the electron releasing power of the monotopic spirocrypta phosphazenes are generally in the following order; five-membered rings $>$ six-membered rings (except III) $>$ seven-membered rings. In this graph, the points also seem as a 'cluster'. In figure $5 \mathrm{c}$, some comparisons were made on the electron releasing power of the substitutents of the phosphazenes. The macrocyclic ring and the nitrogen atoms of pyrrolidines bonded to phosphorus atoms, strongly release electrons to the phosphazene ring. For instance, the $\Delta(P-N)$ values of $\mathbf{4}$ and 7 ; III and IV are respectively 0.061 and $0.058 ; 0.073$ and 0.046 , indicating 


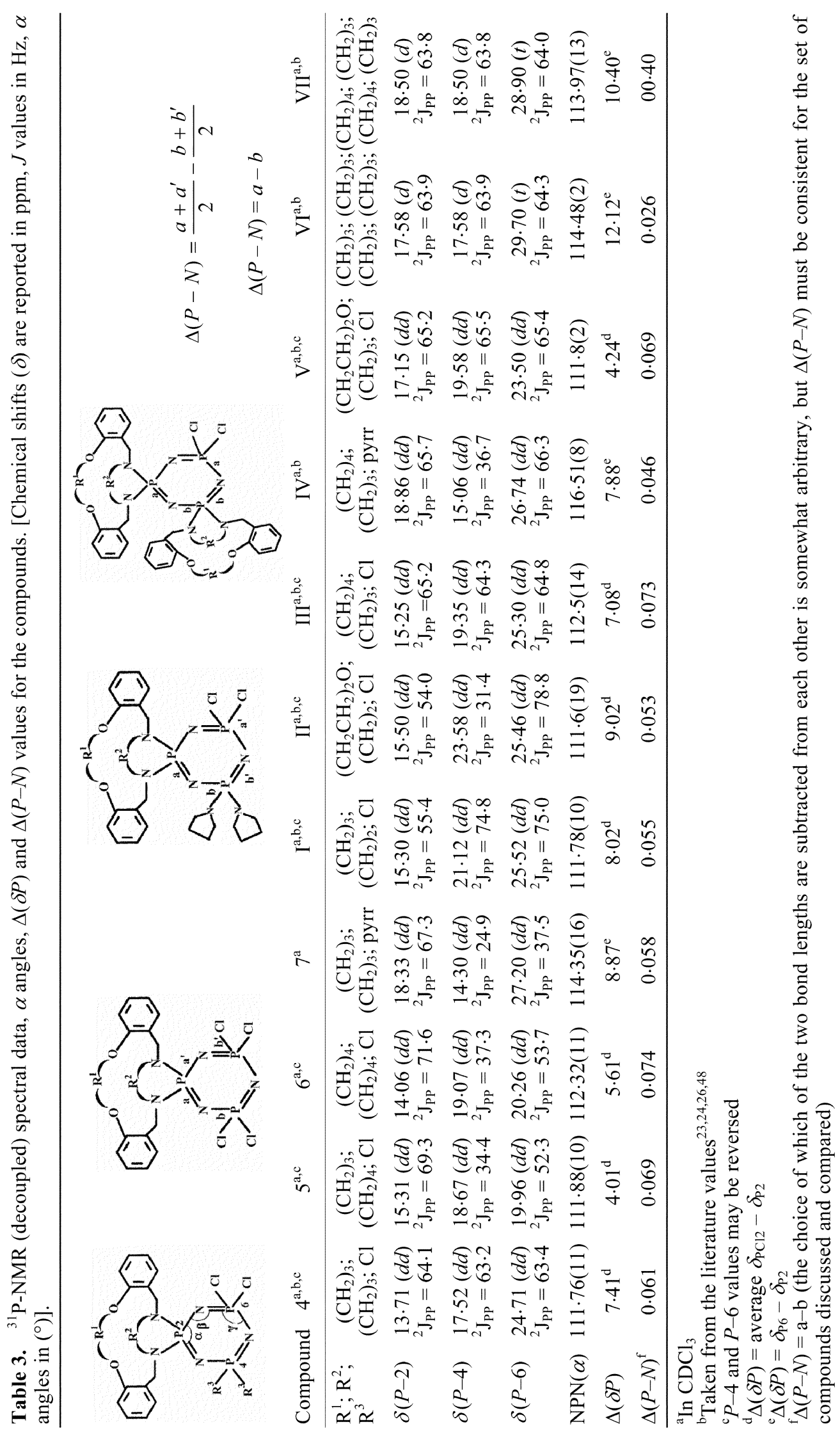


(a)

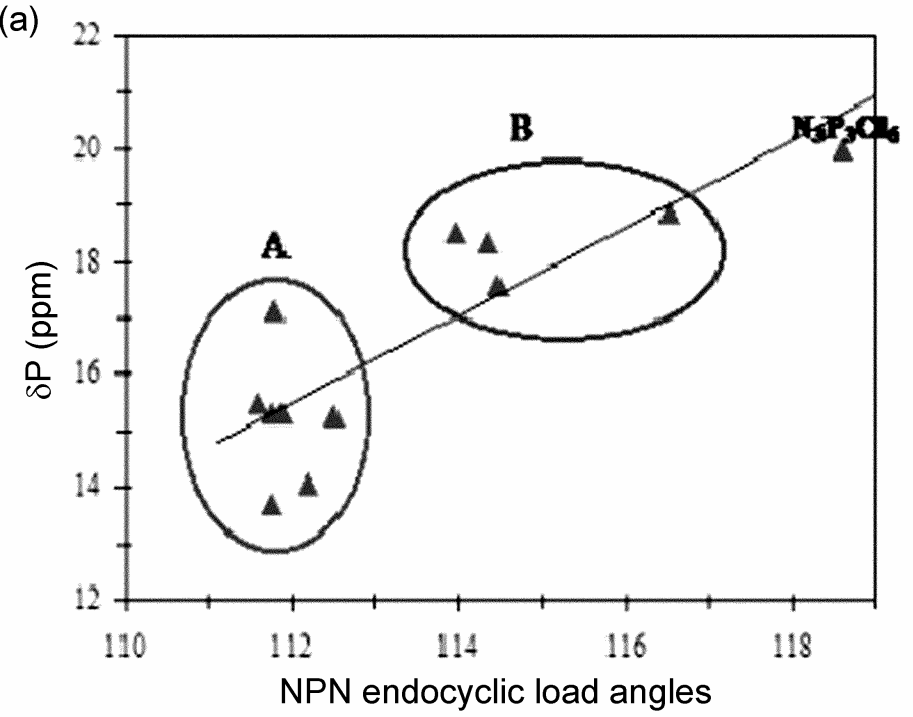

(b)

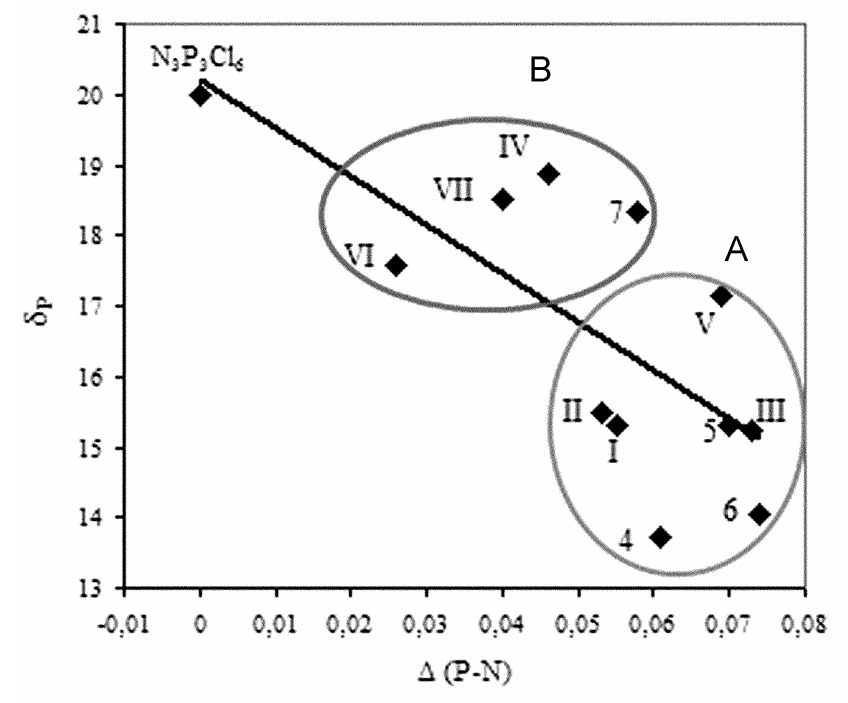

(c)

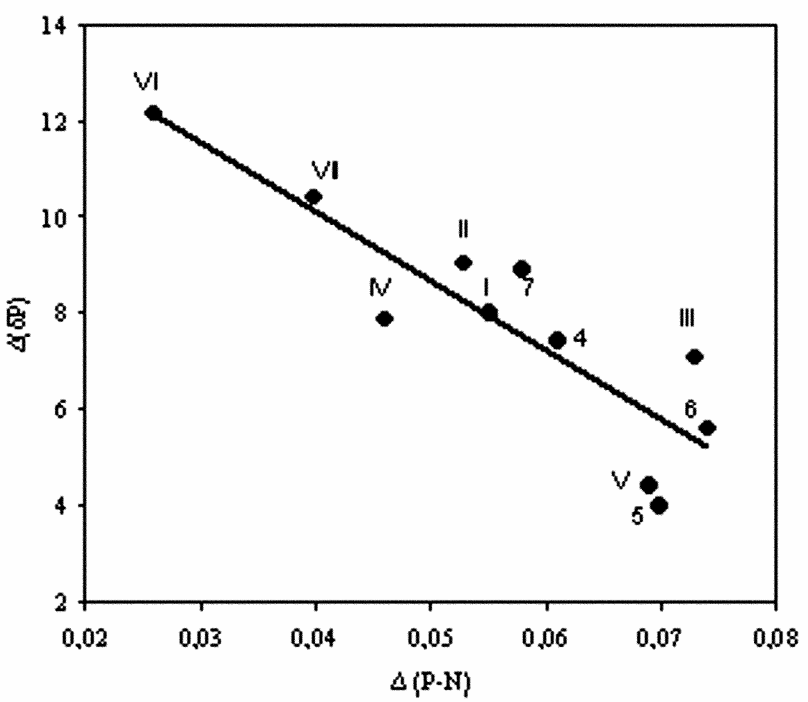

Figure 5. The relationships between (a) $\delta P_{(\text {spiro) }}$-values and endocyclic NPN $(\alpha)$ angles. (b) $\delta P_{(\text {spiro) }}$-values and $\Delta(P-N)$. (c) $\Delta(\delta P)$ values and $\Delta(P-N) . \delta\left(\mathrm{PCl}_{2}\right)$ and the $\alpha$-values of $\mathrm{N}_{3} \mathrm{P}_{3} \mathrm{Cl}_{6}$ are $19 \cdot 60 \mathrm{ppm}, 118 \cdot 30(2)^{\circ}$. ${ }^{52} \mathrm{Region} \mathrm{A}$ indicates monotopic tetrachloro-phosphazenes, Region B indicates pyrrolidinyl-substituted and ditopic spirocrypta phosphazenes.

that the electron releasing powers of pyrrolidine groups in $\mathbf{7}$ and $\mathbf{I V}$ are greater than those of the chloro groups in $\mathbf{4}$ and III (table 3 ).

In all of the spiro-crypta phosphazene architectures, the ${ }^{1} \mathrm{H}$ - and ${ }^{13} \mathrm{C}$-NMR peaks were assigned on the basis of the chemical shifts, multiplicities and coupling constants (table 4). The assignments were made by HETCOR and HMBC (table 5). The HETCOR and HMBC spectra of 5 are illustrated in figures $6 \mathrm{a}$ and $6 \mathrm{~b}$, as an example, and all of the ${ }^{1} \mathrm{H}-$ and ${ }^{13} \mathrm{C}$ NMR assignments have been written on the spectra.
According to the NMR data, all the molecules appear to have symmetric structures in solution. These compounds give complex ${ }^{1} \mathrm{H}-\mathrm{NMR}$ spectra since all of the aliphatic protons are diastereotopic. The benzylic $\mathrm{Ar}-\mathrm{CH}_{2}$ diastereotopic protons are clearly separated from each other and can easily be distinguished. One of the peak groups is in the range of $\delta 3.21-3.84 \mathrm{ppm}$, while the others are in the range of $\delta 4.77-4.87 \mathrm{ppm}$. The benzylic protons give rise to an $\mathrm{ABX}$ spin system due to the geminal proton-proton coupling and the vicinal coupling 
Table 4. ${ }^{1} \mathrm{H}$ - and ${ }^{13} \mathrm{C}-\mathrm{NMR}$ (decoupled) spectral data of 5, 6 and 7 [ $\delta$ are reported in ppm, J values in $\left.\mathrm{Hz}\right]$.

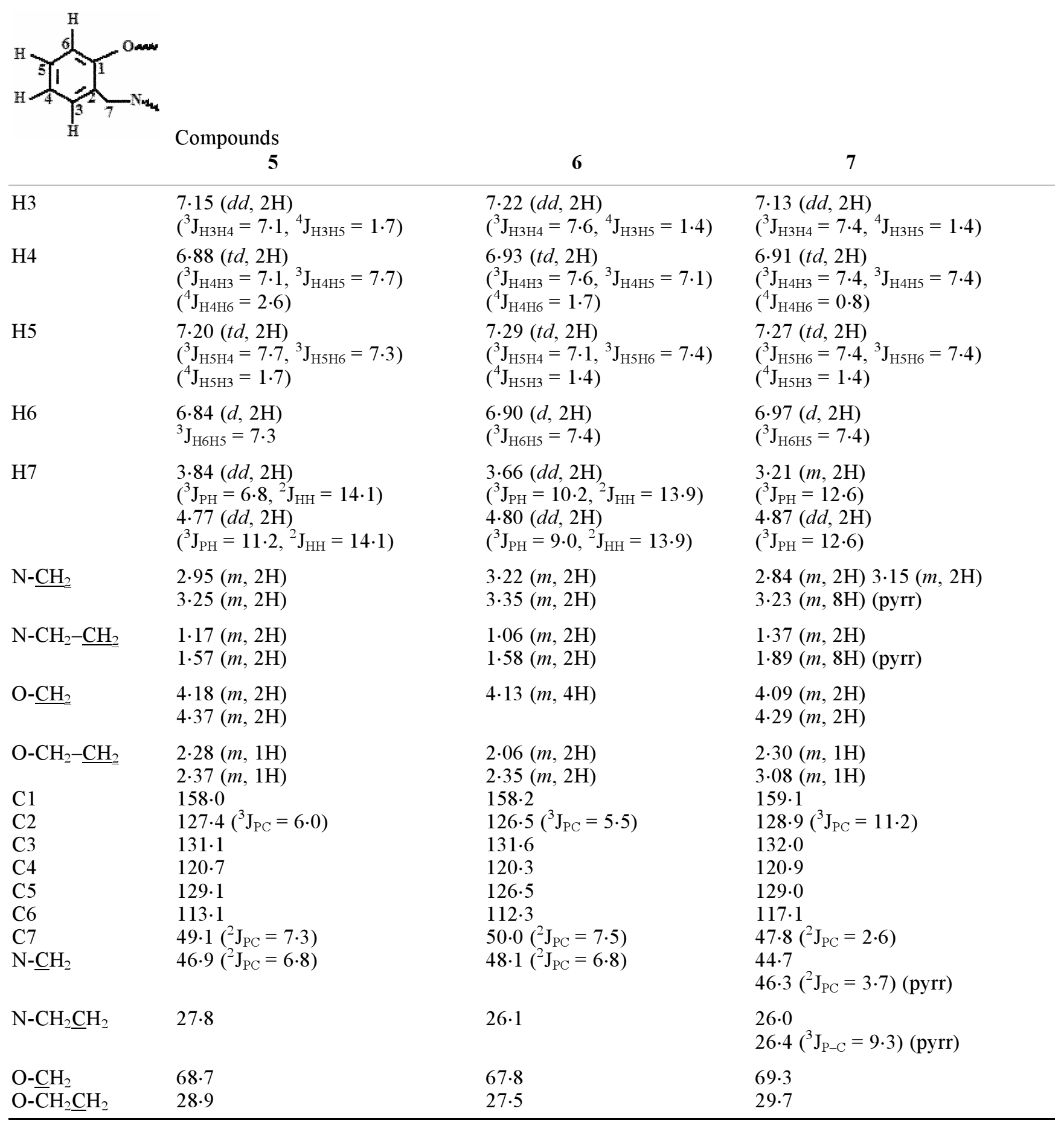

with the phosphorus-31 nucleus. The ${ }^{3} \mathbf{J}_{\mathrm{PH}}$ for benzylic protons of $\mathbf{5}$ and $\mathbf{6}$, which have sevenmembered spiro-rings $\left({ }^{3} \mathrm{~J}_{\mathrm{PH}} \approx 14.0 \mathrm{~Hz}\right)$, are slightly larger than those of $4^{24}$ and 7 , which have sixmembered spiro-rings $\left({ }^{3} \mathbf{J}_{\mathrm{PH}}=12.6 \mathrm{~Hz}\right)$, and $\mathbf{I}^{24}$ and II, ${ }^{26}$ which have five-membered spiro-rings $\left({ }^{3} \mathrm{~J}_{\mathrm{PH}}=10 \cdot 1 \mathrm{~Hz}\right)$. In addition, the $\mathrm{N}-\underline{\mathrm{CH}}_{2}$ and $\mathrm{N}-$
$\mathrm{CH}_{2}-\underline{\mathrm{CH}}_{2}$ protons are observed at $\delta 2 \cdot 84-3 \cdot 22 \mathrm{ppm}$ and $\delta 3.25-3.35 \mathrm{ppm} ; \delta 1.06-1.37 \mathrm{ppm}$ and $\delta 1.57-$ $1.58 \mathrm{ppm}$, respectively as two groups of multiplets.

In ${ }^{13} \mathrm{C}-\mathrm{NMR}$ spectra of 5 and $\mathbf{6}$ the two bondcoupling constants, ${ }^{2} \mathrm{~J}_{\mathrm{PC}}$ of $\mathrm{N}-\underline{\mathrm{CH}}_{2}(6.8 \mathrm{~Hz}$ for 5 and $6.8 \mathrm{~Hz}$ for 6) and $\mathrm{Ar}-\underline{\mathrm{CH}}_{2}(7.3 \mathrm{~Hz}$ for 5 and $7.5 \mathrm{~Hz}$ for 6) are larger than those of the three bond-coupling 
Table 5. $2 \mathrm{D}{ }^{1} \mathrm{H}^{-13} \mathrm{C}$ HETCOR and HMBC correlations for 5 .

\begin{tabular}{|c|c|c|c|c|c|c|}
\hline \multirow[b]{2}{*}{ Atom $\left({ }^{1} \mathrm{H}-\mathrm{NMR}, \mathrm{ppm}\right)$} & \multirow[b]{2}{*}{ HETCOR ${ }^{1} \mathrm{~J}$} & \multicolumn{5}{|c|}{$\mathrm{HMBC}[\mathrm{J}(\mathrm{C}, \mathrm{H})]$} \\
\hline & & ${ }^{2} \mathrm{~J}$ & ${ }^{3} \mathrm{~J}$ & ${ }^{4} \mathbf{J}$ & ${ }^{5} \mathrm{~J}$ & intra J \\
\hline H3 & $\mathrm{C} 3$ & $\mathrm{C} 2, \mathrm{C} 4$ & $\mathrm{C} 1, \mathrm{C} 5, \mathrm{C} 7$ & $\mathrm{C} 6$ & $\mathrm{C} 8$ & \\
\hline $\mathrm{H} 4$ & $\mathrm{C} 4$ & $\mathrm{C} 3, \mathrm{C} 5$ & $\mathrm{C} 2, \mathrm{C} 6$ & $\mathrm{C} 7$ & - & \\
\hline H5 & $\mathrm{C} 5$ & $\mathrm{C} 6, \mathrm{C} 4$ & $\mathrm{C} 3, \mathrm{C} 1$ & - & - & \\
\hline H6 & C6 & $\mathrm{C} 1, \mathrm{C} 5$ & $\mathrm{C} 4, \mathrm{C} 2$ & C3, C7 & - & \\
\hline H7 (3.84 ppm) & $\mathrm{C} 7$ & $\mathrm{C} 2$ & $\mathrm{C} 1, \mathrm{C} 3, \mathrm{C} 8$ & - & $\mathrm{C} 5$ & \\
\hline $\mathrm{H}^{\prime}(4.77 \mathrm{ppm})$ & $\mathrm{C} 7$ & $\mathrm{C} 2$ & $\mathrm{C} 1, \mathrm{C} 3, \mathrm{C} 8$ & $\mathrm{C} 6$ & $\mathrm{C} 5$ & \\
\hline H8 (2.95 ppm) & $\mathrm{C} 8$ & C9 & $\mathrm{C} 7$ & - & - & $\mathrm{C} 10$ \\
\hline $\mathrm{H}^{\prime}(3.25 \mathrm{ppm})$ & $\mathrm{C} 8$ & C9 & $\mathrm{C} 7$ & - & - & \\
\hline H9 (1.17 ppm) & C9 & $\mathrm{C} 8$ & - & - & - & \\
\hline $\mathrm{H} 9^{\prime}(1.57 \mathrm{ppm})$ & C9 & $\mathrm{C} 8$ & - & - & - & \\
\hline H10 (4.18 ppm) & $\mathrm{C} 10$ & C11 & $\mathrm{C} 1$ & - & - & \\
\hline $\mathrm{H} 10^{\prime}(4.37 \mathrm{ppm})$ & $\mathrm{C} 10$ & $\mathrm{C} 11$ & $\mathrm{C} 1$ & $\mathrm{C} 2$ & $\mathrm{C} 3$ & C9 \\
\hline H11 & C11 & $\mathrm{C} 10$ & - & - & - & $\mathrm{C} 8, \mathrm{C} 9$ \\
\hline
\end{tabular}
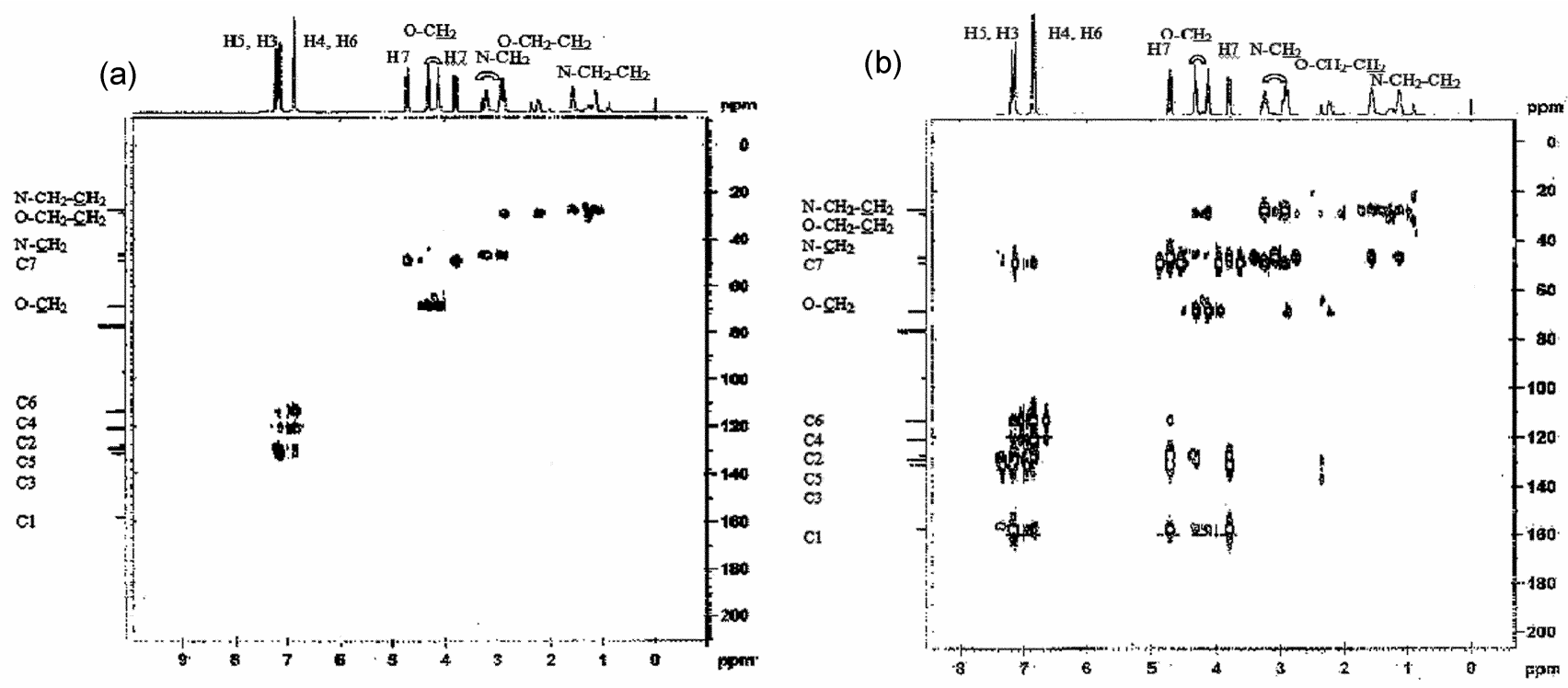

Figure 6. (a) The HETCOR and (b) HMBC spectra of compound 5.

constants, ${ }^{3} \mathrm{~J}_{\mathrm{PC}},(6 \cdot 0 \mathrm{~Hz}$ for 5 and $5 \cdot 5 \mathrm{~Hz}$ for $\mathbf{6})$ of $\mathrm{C} 2$ carbons. For the pyrrolidinyl-substituted phosphazene $7,{ }^{2} J_{\mathrm{PC}}$ values of $\mathrm{N}-\mathrm{CH}_{2}$ and $\mathrm{Ar}-\underline{\mathrm{C}} \mathrm{H}_{2}$ are much smaller than the corresponding values of 5 and $\mathbf{6}$ (table 4). In addition, the ${ }^{2} \mathrm{~J}_{\mathrm{PC}}$ of Ar- $\mathrm{CH}_{2}$ of the spiro-crypta phosphazenes are in the following order: sevenmembered spiro-ring $\left(\mathbf{5}, \mathbf{6}\right.$ and $\left.\mathrm{C}_{22} \mathrm{H}_{28} \mathrm{Cl}_{4} \mathrm{~N}_{5} \mathrm{O}_{3} \mathrm{P}_{3}{ }^{25}\right)>$ five-membered spiro-ring (I) ${ }^{24}>$ six-membered spiro-ring $\left(4,7\right.$, III, $\mathrm{C}_{19} \mathrm{H}_{22} \mathrm{Cl}_{4} \mathrm{~N}_{5} \mathrm{O}_{2} \mathrm{P}_{3}$ and $\mathrm{C}_{29} \mathrm{H}_{42}$ $\left.\mathrm{Cl}_{2} \mathrm{~N}_{7} \mathrm{O}_{3} \mathrm{P}_{3}\right){ }^{23,25}$ As expected, the signals of the nonprotonated carbon atoms disappear in the DEPT spectrum (figure $7 b$ ), as compared with the ${ }^{1} \mathrm{H}$ decoupled ${ }^{13} \mathrm{C}$-NMR spectrum (figure 7a).

\section{$3.3 X$-Ray analysis of 5,6 and 7}

In order to further corroborate the structural assignments, single crystal X-ray structures of compounds 5, 6 and 7 are reported. The phosphazene rings of 5 and 7 are nearly planar (figures $1 \mathrm{~b}$ and $3 \mathrm{~b}$ ), while that of $\mathbf{6}$ is not planar and is in twisted form (figure 


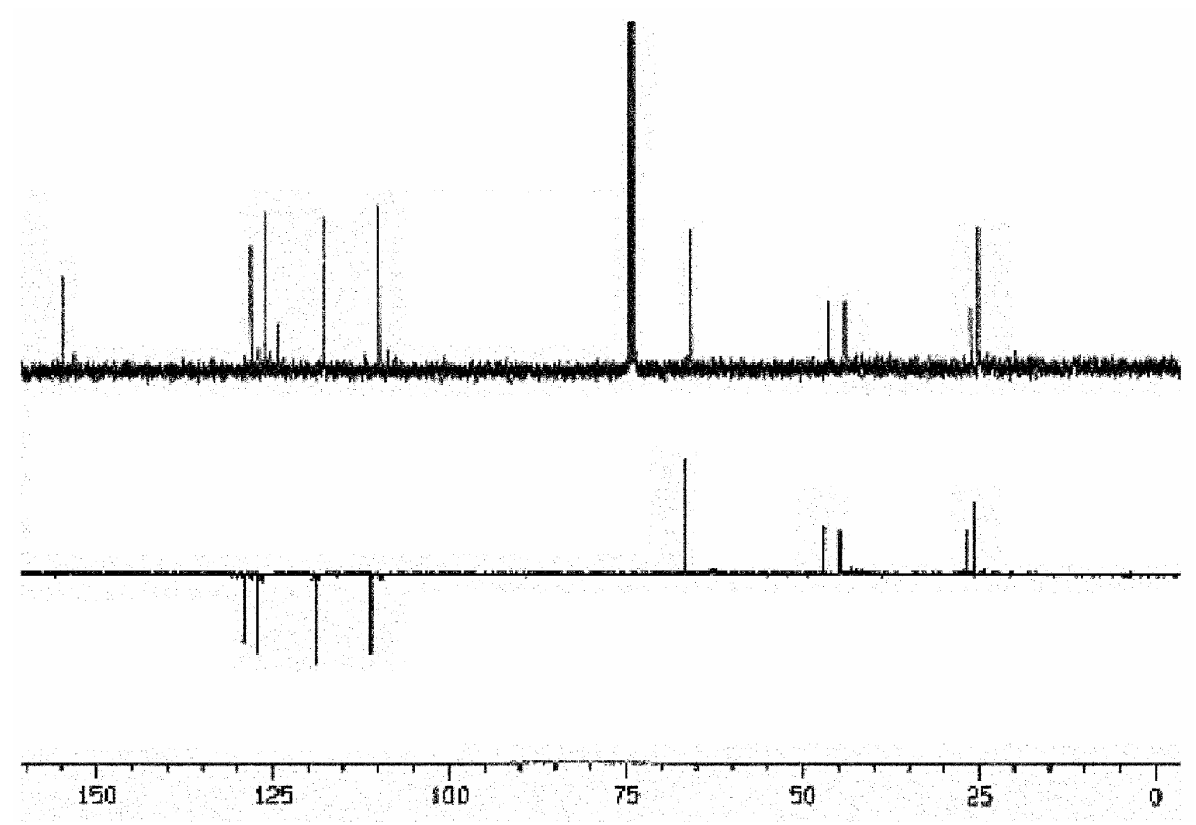

Figure 7. (a) The ${ }^{13} \mathrm{C}-\mathrm{NMR}$ and (b) DEPT spectra of compound 5.

$2 \mathrm{~b} ; \varphi_{2}=-0.2(7)^{\circ}$ and $\left.\theta_{2}=53.3(5)^{\circ}\right)$ having total puckering amplitudes $\mathrm{Q}_{\mathrm{T}}$ of 0.038(2), 0.181(2) and $0.075(6)$, for $\mathbf{5 , 6}$ and 7 , respectively. ${ }^{53}$

In 5, the seven-membered ring $(\mathrm{P} 1 / \mathrm{N} 4 / \mathrm{N} 5 / \mathrm{Cl}-\mathrm{C} 4)$ is in chair conformation ((figure 1c); $\mathrm{Q}_{\mathrm{T}}=0.792(2) \AA$, $\varphi_{2}=-49 \cdot 1(3), \varphi_{3}=-74.4(2)$ and $\left.\theta_{2}=36 \cdot 6(2)\right]$. In 6, the seven-membered ring $(\mathrm{P} 1 / \mathrm{N} 4 / \mathrm{N} 5 / \mathrm{Cl}-\mathrm{C} 4)$ is in twisted form (figure $2 \mathrm{c} ; \mathrm{Q}_{\mathrm{T}}=0.836(2) \AA, \varphi_{2}=106.0$ $(2)^{\circ}, \varphi_{3}=97.0(2)^{\circ}$ and $\left.\varphi_{2}=39.6(2)^{\circ}\right)$. In 7 , the sixmembered ring $(\mathrm{P} 1 / \mathrm{N} 4 / \mathrm{N} 5 / \mathrm{C} 1-\mathrm{C} 3)$ is in chair conformation (figure $3 \mathrm{c} ; \mathrm{Q}_{\mathrm{T}}=0.580(6) \AA, \varphi_{2}=169 \cdot 1(3.9)^{\circ}$ and $\left.\theta_{2}=169 \cdot 7(7)^{\circ}\right)$. As expected, none of the macrocyclic rings are planar with the puckering amplitudes $\mathrm{Q}_{\mathrm{T}}$ of 2.950(3) $\AA$ (for 5), 3.804(3) $\AA$ (for 6) and 2.510(8) $\AA$ (for 7).

The average $\mathrm{P}-\mathrm{N}$ bond lengths in phosphazene rings of 5, 6 and 7 are 1.581(2), 1.563(2), and 1.584(3) $\AA$, which are shorter than the average exocyclic P-N bonds of 1.627(2), 1.627(2) and $1.642(5) \AA$ for 5, 6 and 7, respectively. The sum of the bond angles around the $\mathrm{N}$ atoms in the six and seven-membered spiro-cyclic rings are $\left[359.4(2)^{\circ}\right.$ and $\left.359.8(2)^{\circ}\right]$ for $5,[359.8(2)$ and 357.9(2)] for $\mathbf{6}$, $\left[348.6(2)^{\circ}\right.$ and $\left.349.7(2)^{\circ}\right]$ for 7 , which approve that the $\mathrm{N}$ atoms in 7 have pyramidal geometries. Hence, they may have stereogenic configurations, as in compound $4{ }^{24}$ As can be seen from tables 2 and 3; in $\mathbf{5}$ and 6, $\alpha$ angles are narrowed, while $\alpha^{\prime}$ and $\beta$ angles are expanded considerably with respect to the corresponding values in the 'standard' compound
$\mathrm{N}_{3} \mathrm{P}_{3} \mathrm{Cl}_{6}$. In $\mathrm{N}_{3} \mathrm{P}_{3} \mathrm{Cl}_{6}$, the $\alpha, \alpha^{\prime}$ and $\beta$ angles are 118.3(2), $101.2(1)$ and $121.4(3)^{\circ}$, respectively. ${ }^{52}$ In compound 7 , the $\alpha(\mathrm{N} 1-\mathrm{P} 1-\mathrm{N} 3)[114.35(16)]$ and $\gamma(\mathrm{N} 1-\mathrm{P} 2-$ N2) $\left[114.0(2)^{\circ}\right]$ angles are narrowed, while $\beta(\mathrm{P} 2-$ $\mathrm{N} 1-\mathrm{P} 1)\left[127 \cdot 7(2)^{\circ}\right]$ angle is highly expanded, due to the electron back-donation of the nitrogen atoms of spiro- and pyrrolidine rings, as explained in figures $5 \mathrm{~b}$ and $5 \mathrm{c}$. The narrowing in the $\alpha$ and $\gamma$ angles imply that strong electron donations from the exocyclic $\mathrm{N}$ atoms to the $\mathrm{N}_{3} \mathrm{P}_{3}$ phosphazene rings have occurred. The electron back-donation also causes the shortening of the exocyclic $\mathrm{P}-\mathrm{N}$ bonds.

The inner hole-sizes of the macrocycles in the radii of 5, 6 and 7, estimated as twice the mean distance of the donor atoms from their centroids, are approximately $1.36 \AA$ (for 5), $1.55 \AA$ (for 6) and $1.46 \AA$ (for 7). The estimations were made by using the 'modified covalent radii' of the, $\mathrm{N}_{\mathrm{sp}}^{2}(0.66 \AA), \mathrm{N}_{\mathrm{sp}}^{3}$ $(0.72 \AA)$ and $\mathrm{O}_{\mathrm{sp}}^{3}(0.76 \AA)$, atoms as in the literature method. ${ }^{54}$

\section{Conclusions}

$\mathrm{N}_{2} \mathrm{O}_{2}$-donor type diaza crown-ethers (1-3) lead to the formation of monotopic spiro-cyclic-cryptaphosphazene architectures (4-6) via the condensation reactions of $\mathrm{N}_{3} \mathrm{P}_{3} \mathrm{Cl}_{6}$. The partial substitution reaction of 4 with excess pyrrolidine results in geminal pyrrolidinyl-substituted phosphazene (7). 
According to the ${ }^{31} \mathrm{P}-\mathrm{NMR}$ spectra of $\mathbf{5}$ and $\mathbf{6}$, these compounds have anisochrony. In addition, spirocyclic nitrogen atoms of 7 are stereogenic, as indicated by the X-ray crystallographic data. The variations of $\delta P$-shifts depend on the steric and electronic factors of bulky substituent, which change the $\alpha, \beta$ and $\gamma$ angles of the phosphazene rings. The correlation between the endocyclic $(\alpha)$ angles with $\delta P_{\text {(spiro)- }}$ shifts of the phosphorus atoms has been investigated. Meanwhile, the relationships between $\Delta(P-N)$ versus the $\delta P_{\text {(spiro) }}$-shifts and $\Delta(d P)$ values have been presented. No linear relationship has been observed. The points appear as a 'cluster' as given in figure 5 .

\section{Supplementary data}

Crystallographic data for the structures reported here have been deposited at the CCDC as supplementary data, CCDC Nos. 666822-666824. Copies of the data can be obtained on application to CCDC, 12 Union Road, Cambridge CB2 1EZ, UK. E-mail: deposit@ccdc.cam.ac.uk.

\section{Acknowledgements}

The authors are indebted to the Department of Chemistry, Atatürk University, Erzurum, Turkey, for the use of X-ray diffractometer purchased under Grant No. 2003/219 of the University Research Fund. The authors acknowledge The Scientific and Technical Research Council of Turkey Grant No. 104T392, and Hacettepe University, Scientific Research Unit Grant No. 0202602002 for financial support.

\section{References}

1. Mark J E and Allcock R W 1992 Inorg. Polym. Printince-Hall Englewood Cliffs NJ

2. Steiner A, Zacchini S and Richards P I 2002 Coord. Chem. Rev. 227193

3. Magro G, Donnadieu B, Spataro G, Caminade A M and Majoral J P 2007 Polyhedron 143885

4. Heyde M, Moens M, Van Vaeck L, Shakesheff K M, Davies M C and Schacht E H 2007 Biomacromolecules 51436

5. Allcock H R 2006 J. Inorg. Organomet. Polym. Mater. 4277

6. Wisian-Neilson P, Jung J H, Potluri S K, Mauldin C E and Zhang H 2004 Phosphorus Sulfur Silicon Relat. Elem. 4-5 817

7. Benson M A, Boomishankar R, Wright D S and Steiner A 2007 J. Organomet. Chem. 6922768
8. Muralidharan K and Elias A J 2003 Inorg. Chem. 42 7535

9. Raab M, Schick G, Fondermann R, Dolg M, Henze W, Weynand U, Gschwind R M and Niecke E 2006 Angew. Chem. Int. Ed. 193083

10. Ungar G 2003 Mol. Crys. and Liq. Cryst. 396155

11. Allcock H R and Kellam III E C 2003 Solid State Ionic 156401

12. Peterson E S, Luther T A, Harrup M K, Klaehn J R, Stone M L, Orme C J and Stewart F F 2007 J. Inorg. and Organomet. Polym. Mater. 17361

13. Allen C W 1991 Chem. Rev. 91119

14. Contractor S R, Kılıç Z and Shaw R A 1987 J. Chem. Soc., Dalton Trans. 2023

15. Shaw R A 1980 Pure Appl. Chem. 521063

16. Kılıç A, Kılıç Z and Shaw R A 1991 Phosphorus Sulfur Silicon Relat. Elem. 57111

17. Wilson M, Lafaille L, Vidaud L and Labarre J E 1987 Phosphorus Sulfur Silicon Relat. Elem. 29147

18. Coles S J, Davies D B, Eaton R J, Hursthouse M B, Kýlýç A, Mayer T A, Shaw R A and Yenilmez G 2002 J. Chem. Soc., Dalton Trans. 365

19. Yıldız M, Kılıç Z and Hökelek T 1999 J. Mol. Struct. 510227

20. Kılıç A, Begeç S, Çetinkaya B, Kılıç Z, Hökelek T, Gündüz N and Yıldız M 1996; Kılıç A, Begeç S, Çetinkaya B, Kılıç Z, Hökelek T, Gündüz N and Yıldız M 1996 Heteroatom Chem. 4249

21. Allcock H R, Sunderland N, Primrose A P, Rheingold A L, Guzei I A and Parvez M 1999 Chem. Mater. 11 2478

22. Carriedo G A, Garcia Alonso F J, Gonzalez P A, Valenzuela C D and Saez N Y 2002 Polyhedron 21 2579

23. İlter E E, Çaylak N, Ipıklan M, Asmafiliz, Kılıç Z and Hökelek T 2004 J. Mol. Struct. 697119

24. Asmafiliz N, İlter E E, Ipıklan M, Kılıç Z, Tercan B, Çaylak N, Hökelek T and Büyükgüngör O $2007 \mathrm{~J}$. Mol. Struct. 832172

25. Bilge S, Demiriz Ş, Okumus A, Kılıç Z, Tercan B, Hökelek T and Büyükgüngör O 2006 Inorg. Chem. 458755

26. Bilge S, Kılıç Z, Çaylak N and Hökelek T $2004 \mathrm{~J}$. Mol. Struct. $2004 \mathbf{7 0 7} 139$

27. Bilge S, Natsagdorj A, Demiriz Ş, Çaylak N, Kılıç Z and Hökelek T 2004 Helvetica Chim. Acta. 872088

28. Carriedo G A, Garcia-Alonso J F, Garci'a-Alvarez L J, Pappalardo G C, Punzo F and Rossi P 2003 Eur. J. Inorg. Chem. 2413

29. Shimono S, Takahashi H, Sakai N, Tamura R, Ikuma N, Yamauchi J 2005 Mol. Cryst. Liq. Cryst. 44037

30. Gleria M and De Jaeger R 2001 J. Inorg. Organometallic Polymers 111

31. Bilge $S$, Özgüç B, Demiriz Ș, İșler H, Havyalı M, Kılıç Z and Hökelek T 2005 J. Mol. Struct. 748101

32. Hökelek T, Akduran N, Yıldız M, Dal H and Kılıç Z 2000 Acta Crystallogr. C56 90

33. Öztürk L, Hökelek T, Dal H and Kılıç Z 2001 Acta Crystallogr. E58 20

34. Beșli S, Coles S J, Davarcı, D, Davies D B, Hursthouse M B and Kılıç A 2007 Polyhedron 265283 
35. Satish Kumar N and Kumara Swamy K C 2004 Polyhedron 23979

36. Bhuvan Kumar N N and Kumara Swamy K C 2008 Chirality 20781

37. Beşli S, Coles S J, Davies D B, Hursthouse M B, Kılıç A and Shaw R A 2007 Dalton Trans. 2792

38. Perin D D, Armarego W L and Perrin D R 1980 Purification of laboratory chemicals (Oxford: Pergamon), 2nd edn

39. Bruker program 1D WIN-NMR (release 6.0) and 2D WIN-NMR (release 6.1)

40. Grimsley P G, Lindoy L F, Lip 1-1 C, Smith R J and Baker J T 1977 Aust. J. Chem. 302095

41. Adam K R, Clarkson C, Leong A J, Lindoy L F, McPartlin M, Powell H R and Smith S V 1994 J. Chem. Soc., Dalton Trans. 2791

42. Blessing R H 1995 Acta Crystallogr. A51 33

43. Sheldrick G M 1997 SHELXS-97 and SHELXL-97 University of Göttingen Germany

44. Farrugia L J 1997 J. Appl. Crystallogr. 30565
45. Lensink C, de Ruiter B and van de Grampel J C 1984 J. Chem. Soc., Dalton Trans. 1521

46. Shaw R A 1976 Z. Naturforsch. Teil B31 641

47. Alkubaisi A H, Hursthouse M B, Shaw L S and Shaw R A 1988 Acta Crystallogr. B44 16

48. Tercan $B$, Hökelek $T$, Büyükgüngör $O$, Asmafiliz N, İlter E E and Kılıç Z 2005 Acta Crystallogr. E61 o2145

49. İlter E E, Asmafiliz N, Kılıç Z, Ipıklan M, Hökelek T, Çaylak N and Şahin E 2007 Inorg. Chem. 469931

50. Contractor S R, Hursthouse M B, Shaw L S and Shaw R A 1985 Acta Crystallogr. B41 122

51. Beșli S, Coles S J, Davies D B, Hursthouse M, Kılıç A, Mayer T and Shaw R A 2002 Acta Crystallogr. B58 1067

52. Bullen G J 1971 J. Chem. Soc. A 1450

53. Cremer D and Pople J A 1975 J. Am. Chem. Soc. 97 1354

54. March J 1992 Advanced organic chemistry reactions mechanisms and structure (New York: Wiley) 4th edn) p. 4 